DOI: http://dx.doi.org/10.5007/1980-3532.2015n14p67

\title{
O diário de campo como recurso didático-pedagógico para a disciplina sociologia no ensino médio
}

\author{
The field diary as a didactic - pedagogic resource for sociology \\ discipline in high school
}

\author{
Andre Luis Santos de Souza \\ Universidade Federal de Viçosa (UFV) \\ Professor de sociologia (rede privada de ensino/MG) \\ andreconatus@gmail.com
}

\begin{abstract}
Resumo: Este artigo mobiliza uma experiência etnográfica envolvendo uma sequência de aulas, na turma de primeiro em uma escola privada na cidade de Ponte Nova, MG. O objetivo é elucidar algumas reflexões e análises envolvendo o ensino de ciências sociais na escola através da disciplina sociologia. As evidências mobilizadas ao logo do texto apoiam-se na experiência pedagógica envolvendo o tema "tecnologias e mídia", tendo como principal recurso didático o "diário de campo". Foi possível concluir que: a didática capaz de envolver diretamente os estudantes e seus contextos durante a interação em sala de aula é garantia de maior adesão do alunato à disciplina e aos conhecimentos científicos por ela mobilizados. No caso analisado, o envolvimento da realidade dos estudantes com os usos e relações com as novas tecnologias de informação e comunicação (NTIC), ajudou na produção de conhecimento através da relação "conceito, teoria e tema".
\end{abstract}

Palavras chave: aula. ciências sociais. ensino. interação. NTIC.

\begin{abstract}
This article mobilizes an ethnographic experiment involving a sequence of classes, the first class in a private school in the city of Ponte Nova, MG. The goal is to elucidate some reflections and analyzes involving the teaching of social sciences at school through the sociology discipline. Evidence mobilized the logo text support on the educational experience involving the theme "technologies and media" , the main teaching resource the " diary ". It was concluded that : the didactic able to directly involve students and their contexts during the interaction in the classroom is higher bond guarantee alunato discipline and scientific knowledge for it mobilized. In the case analyzed, the involvement of the reality of students with the uses and relations with the new information and communication technologies ( ICT), helped in the production of knowledge through the relationship "concept, theory and theme ."
\end{abstract}

Keywords: class. social Sciences. teaching. interaction. NICT

Originais recebidos em: 29/02/2016

Aceito para publicação em: 06/07/2016

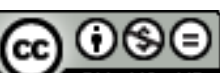

EY NC ND Este trabalho está licenciado sob uma Licença Creative Commons Atribuição-Uso NãoComercial-Vedada a criação de obras derivadas 3.0 Unported License.

Revista Em Debate (UFSC), Florianópolis, volume 14, p. 67-81, 2015. ISSNe 1980-3532 


\section{Introdução}

O ensino de ciências sociais nos três últimos anos da formação escolar básica, a partir da regulamentação definida pela Lei 11.684/2008, tem se tornado um desafio e um campo de estudo para antropólogos, sociólogos e cientistas políticos. Desse modo, torna-se necessário, na atualidade, pensar sobre a formação de professores e a construção de bases didático-pedagógicas que garantam a transposição linguística de conceitos teóricos fundamentais das ciências sociais. Nesse sentido, conceitos, teorias e temas precisam ser adaptados para um novo público: os jovens do ensino médio. Sendo assim o objetivo desse artigo é refletir e analisar, a partir de uma experiência etnográfica de sala de aula, o uso do diário de campo enquanto recurso didático-pedagógico.

Nesse sentido, Sayonara Leal e Tauvana Yung ${ }^{1}$ realizaram estudos de caso em escolas públicas e privadas no Distrito Federal. Essas pesquisadoras investigaram (a partir de observação participante, entrevistas quantitativas e grupos focais) a "relação entre finalidade intelectual atribuída à disciplina sociologia no ensino médio e a representação que o alunato faz de sua experiência social com as ciências sociais no espaço escolar" (LEAL \& YUNG, 2015, 773). Elas apontam alguns pontos relevantes com base nos dados e análises acerca da realidade do ensino das ciências sociais nas escolas básicas em Brasília: aos aspectos didático-pedagógicos envolvidos, a perspectiva institucional dado à disciplina, a percepção dos estudantes com os conteúdos das ciências sociais e a aproximação dos jovens do ensino médio dos conhecimentos das ciências sociais.

É possível dizer que grande parte da simpatia que o alunato terá ou não pela disciplina possui uma relação direta com a didática e a capacidade do professor de mobilizar conceitos fundamentais das ciências sociais. Além disso, outro ponto importante é refletir sobre a dificuldade apresentada por alguns docentes em "transpor noções teóricas, metodológicas e pragmáticas dessa disciplina para o universo sociocognitivo do alunato do ensino médio" (LEAL \& YUNG, 2015, 790).

É importante destacar que a disciplina sociologia (ou ciências sociais?) deve ser apresentada de modo sistemático com intuito de transpor algumas barreiras para seu ensino

\footnotetext{
${ }^{1}$ Sayonara Leal é professora adjunta do Departamento de Sociologia da Universidade de Brasília (UNB). Tauvana Yung é mestre e doutoranda em sociologia pela UNB.
} 
na escola básica. Ressalta-se, também, que a disciplina pode oferecer elementos importantes para que os jovens estudantes possam desenvolver habilidades diferentes de interpretar os fenômenos sociais, descobrindo o véu das representações e percebendo-as como produtos das relações sociais presentes em seu cotidiano. Ou seja, representações e significações construídas socialmente ao longo dos processos históricos pelos quais passaram a sociedade.

Contudo, o presente artigo se insere no bojo dessa problemática propondo descrever e analisar a experiência dos estudantes matriculados no primeiro ano do ensino médio em uma escola privada, localizada na cidade de Ponte Nova, MG. Pretende-se elucidar o processo de (re)significação dos usos atribuídos às Tecnologias de Informação e Comunicação nos hábitos do alunato. A fim de melhor explicitar o processo envolvendo o cotidiano, os conceitos e teorias das ciências sociais, foi mobilizado um conjunto de dados a partir das interações em sala de aula, de entrevistas, plano de aulas e análise das atividades avaliativas realizadas pelos estudantes.

As situações sociais analisadas se deram durante uma sequência didática de cinco aulas e das experiências cotidianas dos estudantes com os aparelhos celulares e os computadores conectados à internet. Foi possível avaliar a eficácia da mobilização do diário de campo (vista como importante técnica de pesquisa para a antropologia) enquanto recurso didático-pedagógico capaz de despertar interesse no alunato dos conceitos e teoria mobilizados na disciplina sociologia e sua relação à própria realidade social.

O tema trabalhado durante a sequência didática foi "Tecnologias e Mídias". Os conceitos trabalhados em sala de aula foram: "interação social", "Tecnologia", "TIC e NTIC" e "Mídia". De modo articulado, trabalhou-se por meio de uma aula expositiva dialogada a introdução e problemática referente ao tema sugerido pelo livro didático elaborado pela rede salesiana de ensino. Inicialmente os estudantes foram estimulados a refletir sobre o tema, conceitos e teorias buscando por meio de uma "imaginação sociológica" interpretar suas próprias vivências cotidianas (BERGER, 1978).

Com base nas aulas o professor objetivou estimular nos estudantes reflexão acerca da relação do ser humano com os instrumentos tecnológicos criados para intervir e adaptarse ao meio ambiente e social. Fazendo um recorte a intenção voltou-se para às reflexões 
envolvendo os instrumentos criados para alarga a comunicação, percepção e interação entre os indivíduos nas sociedades capitalistas contemporâneas (LÉVY, 2000; 2003).

\section{Estimulando a compreensão de alguns fenômenos sociais}

Estudos arqueológicos e antropológicos têm evidenciado que a relação do ser humano com o meio ambiente, há tempos, tem sido mediada por instrumentos tecnológicos dos mais variados possíveis, em diversas culturas e com diferentes finalidades e significados. Contudo, pensar a relação e significação dada aos objetos pelos seres humanos requer considerar sua historicidade socialmente localizada. Tal concepção torna-se fundamental para analisar os impactos e mudanças produzidas no mundo social com o surgimento e incorporação das Novas Tecnologias de Informação e Comunicação - NTIC.

Nesse sentido, como forma de ilustrar o pressuposto acima apresentado, o professor enunciou para aos estudantes uma anedota narrada pelo antropólogo Roberto DaMatta (1987). Ele conta a história de um pesquisador que vai para uma aldeia indígena fazer um trabalho de campo; logo após sua vivência junto ao grupo é chegado o dia de sua partida, e uma criança chega para se despedir dele e o presenteia com um arco e uma flecha; o estudioso como forma de retribuição tira seu relógio e o entrega para o garoto que sai correndo e o dependura no galho de uma árvore; enquanto o pesquisador assiste a cena, ele estranha a atitude do menino. Retornando para sua sociedade, logo que chega a sua casa, o antropólogo vai até a sala de visitas e procura um lugar adequado para pendurar o arco e a flecha na parede.

Moral da história: o significado ou utilidade dado a determinada tecnologia tem a ver com o contexto de sua criação, ou seja, tem a ver com as redes de conhecimentos e experiências simbólicas suscitadas a partir daí. Entretanto, muitas vezes, as tecnologias extravasam os usos e significações dados em sua comunidade e são incorporadas em outros grupos e culturas em tempos e espaços diferentes.

Partindo dessa anedota, trabalhou-se na introdução das aulas a distinção entre o conceito de "tecnologia" e "NTIC". Esse foi o primeiro passo para iniciar a sequência de aulas planejadas para a disciplina sociologia. Desse modo, o passo seguinte foi traçar uma 
estratégia pedagógica que envolvesse a realidade e vivências cotidianas dos estudantes, para, desse modo, se chegar à abstração teórica e conceitual do conteúdo ministrado.

\section{A interação social na sala de aula: uma sequência didática para a disciplina sociologia}

As aulas (cinco) foram planejadas conforme conteúdo programático definido pelo professor para o terceiro trimestre, com base no material didático utilizado pela escola. Os objetivos traçados para as aulas foram: fazer uma introdução ao tema "Tecnologias e mídias" (mobilizado pelo Caderno de Sociologia 3) e estimular a compreensão de fenômenos sociais envolvendo as Novas Tecnologias de Informação e Comunicação (NTIC); explicitar a interação dos indivíduos na sociedade e os hábitos cotidiano dos estudantes do primeiro ano. Essa turma do ensino médio é composta por 22 indivíduos, com faixa etária variando entre 14 e 16 anos e em sua maioria natural de Ponte Nova.

A primeira aula foi realizada no dia 10 de setembro de 2015. Na ocasião o professor apresentou aos estudantes o plano de organização da disciplina e quais seriam as avaliações referentes ao terceiro (e último) trimestre do calendário escolar. Além disso, o professor apresentou o tema "tecnologias e mídia" por meio de um formato de aula expositivadialogada. Como fechamento dessa aula, o docente debateu com os estudantes sobre as relações sociais e as tecnologias, especialmente as NTIC. No final da aula o professor convidou os estudantes a ajudá-lo a planejar a aula da semana seguinte. Ele solicitou para que de modo voluntário (pois não ira contar pontos na média) os alunos produzissem um diário relatando um dia em sua rotina semanal, descrevendo detalhadamente desde o momento que acordavam até a hora que iam dormir. Finalizou a aula explicando que o "diário de campo" é um importante instrumento de coleta de informações em pesquisas de campo - o que garantiu em sala de aula o caráter científico e autônomo da disciplina sociologia/ciências sociais (SARANDY, 2001).

Na quinta feira do dia 17 de setembro de 2015 foi realizada a segunda aula. O professor iniciou a aula com todos sentados em círculo. Ele explicou que a dinâmica da aula seria cada um ler o seu diário (a começar pelo professor) e, ao mesmo tempo, deveriam anotar quais NTIC eram citadas pelos colegas. Neste dia, a maioria dos estudantes 
manifestou que havia escrito seu diário. Para a surpresa do professor apenas dois estudantes não realizaram a tarefa. Ele explicou como seria a dinâmica da aula pedindo para que um aluno o ajudasse escrevendo palavras chaves na lousa digital. O professor inicia lendo seu diário tecendo comentário e ouvindo outros de algum jovem. Feito isso, foi à vez de cada estudante fazer o mesmo exercício.

Enquanto os alunos iam fazendo a leitura de seus diários o professor ia destacando pontos importantes que poderiam ser mobilizados para analisar a relação das NTIC e os hábitos da população jovem pontenovense. $\mathrm{O}$ docente mobiliza oportunamente a teoria de Pierre Bourdieu (2004) e comenta sobre seu conceito habitus. Terminado o tempo da aula (50 min.) ainda faltava metade da turma para ler os diários. Diante disso, o professor reorganizou sua estratégia de aula e combinou com os jovens de continuar o exercício da leitura e análise dos diários na próxima aula.

Então, na terceira aula realizada no dia 24 de setembro de 2015, os estudantes continuaram fazendo a leitura de seus diários. O professor pediu para que um deles o ajudasse com as anotações na lousa digital. Enquanto os jovens faziam a leitura de seus diários o professor pediu para seu ajudante fosse anotando quais as Tecnologias de Informação que eram citadas pelos diários e qual sua relação dentro da rotina narrada.

No final dessa aula o docente convidou os estudantes a fazer uma reflexão geral sobre os conteúdos analisados a partir dos diários. Em seguida entregou-lhes fichas com instruções para a atividade avaliativa, que foi realizada em casa e entregue na aula (seguinte valendo dois pontos na média do trimestre). Esta atividade consistia em ter que desenhar um mapa da cidade indicando o trajeto que eles faziam rotineiramente e os espaços que mais utilizavam (casa, praça, escola, etc); e nestes locais indicar qual NTIC era mobilizada.

A quarta aula foi realizada no dia 1 de outubro 2015. Através de slides o professor inicia a aula, ressaltando seu caráter mais expositivo, ou seja, de caráter mais teórico, buscou discutir alguns trechos retirados do livro didático. O objetivo era suscitar nos estudantes a relação entre teoria, conceitos e os dados retirados dos diários.

Conforme o professor ia apresentando os slides, indagava com os alunos sobre "o que é tecnologia?", "o que é mídia", "as tecnologias de comunicação tem a possibilidade de ampliar as interações e as transformá-las?", "você faz parte da população que não vive sem tecnologias? Qual delas é indispensável para sua vida?” e ainda, “é possível o 
desenvolvimento tecnológico com a preservação do ambiente e da qualidade de vida humana?" (ZENUN \& MARKUNAS, 2013, p.9-17). Ao final dessa aula o professor recolheu as tarefas desenvolvidas pelos alunos e combinou com eles de trazer no próximo encontro uma síntese e descrição dos dados para que os alunos pudessem analisá-los junto com o professor.

A partir desse momento, a interação proporcionara a culminância da "produção inicial" traçada pela "sequência didática" (DOLZ J.; NOVERRAZ M.; SCHENEUWLY B., 2003, p.98). Para a última aula (momento da produção final) foi planejado realizar uma exposição dos dados em um texto de word no formato de uma relatório de pesquisa. Neste documento foi sistematizado um detalhamento do problema, os objetivos, justificativas e análise da relação das NTIC nos hábitos dos indivíduos e no contexto local como tais tecnologias estavam inseridas na rotina dos jovens pontenovenses.

Durante a aula o docente estimulou os estudantes a fazerem leitura da descrição dos dados e ajudarem a analisar a relação entre eles e a realidade vivenciada pelo pela turma do primeiro ano do ensino médio. Para tanto, o professor exercitou com o alunato uma interpretação sociológica dos dados a luz de referencias teóricas apresentadas no livro didático e em bibliografias complementares, como por exemplo, José Manuel Moran (2006), Pierre Bourdieu (2004; 2008) e Pierre Lévy (2000; 2003).

Desse modo, na quinta aula, realizada no dia 8 de setembro de 2015, os dados fornecidos pelos estudantes (através dos diários e atividade mapa-cognitivo) serviram de base para analisar os hábitos cotidianos a partir das experiências particulares de cada um. Nesse encontro, os jovens foram estimulados a observar o familiar através da ótica das ciências sociais (VELHO, 1978).

A intenção de mobilizar o tema "tecnologias e mídia" por meio dessa sequência didática foi mostrar a partir de um olhar de fora (o do professor) uma perspectiva de dentro, aproximando os estudantes da disciplina e, ao mesmo tempo, dos conteúdos curriculares por ela mobilizados. Tal movimento seria positivo para despertar o interesse nos jovens pelos conhecimentos das ciências sociais e pela disciplina sociologia (LEAL \& YUNG, 2015, 784).

A integração das NTIC é uma realidade já naturalizada no cotidiano desses jovens. Os usos e significados são variados sendo em alguns momentos institucionalizado e outros 
não. Por exemplo, apareceu nos relatos dos diários que muitos dos alunos navegam na internet e interagem com amigos pelo celular e ou computador em seus quartos, sozinhos, deitados já prontos para dormir. Muitos dormem entre meia noite e uma hora da manhã e acordam às seis horas da manhã para chegar à escola por volta das sete horas.

Os estudantes relataram que em casa fazem uso de aparelhos de televisão, computadores e aparelhos celulares conectados à internet. Quase todos iam para a escola de carro, van e/ou ônibus e no caminho ouviam música pelo celular e jogavam vídeo game. No espaço escolar também indicaram fazer uso das NTIC, em especial a Lousa Digital², computador e celular conectados à internet (muitos acessam o livro didático digital). Com base nessa evidência o professor debateu com os estudantes o quanto essas tecnologias e seus dispositivos impactaram na vida estudantil.

Com a incorporação das NTIC no espaço escolar, os processos de ensino e aprendizagem ficaram mais dinâmicos e ao mesmo tempo aproximou a dimensão da escola e da casa, alterando o espaço escolar para além do físico. Com a internet e seus dispositivos tecnológicos o alunato poderia, em casa, ter acesso à escola de modo virtual. O "tempo escolar" poderia extravasar o "estar na escola" (no sentido físico) e adentrar em outros espaços como o da casa, alterando o "tempo de lazer" desses jovens. Por exemplo, quando eles eram estimulados pela escola a utilizar a Plataforma Geekie (on line) para realizar tarefas, estudos complementares e simulados de questões.

Através dessa plataforma o professor pode visualizar os relatórios dos alunos que fizeram ou não a tarefa e, ainda, qual conteúdo eles tiveram menor rendimento nas questões propostas pelos simulados. Essa ferramenta didático-pedagógica de um lado dinamiza os processos de ensino e aprendizagem e, por outro lado, garante maior vigilância sobre a postura dos estudantes em relação ao compromisso com os estudos.

Notou-se que o celular conectado ou não à internet é a NTIC mais recorrente nas ações dos estudantes durante sua rotina diária. O celular está presente desde o momento em que eles acordam até o momento que vão dormir e às vezes o utilizado concomitante ao hábito de assistir televisão. Alguns relataram que no momento de dormir ainda interagiam virtualmente com amigos pelo whatsapp e facebook.

\footnotetext{
${ }^{2}$ Uma tecnologia que funciona como uma grande tela de computador que permite interatividade a partir do toque com uma caneta que funciona como um mouse. Permite exibir vídeos, abrir mapas, mobilizar fotografias, textos em geral e ainda utilizar recurso da tela branca para escrever e anotar durante a aula.
} 
Com base nesses dados é possível perceber o quanto as tecnologias de informação e comunicação estão presentes nos hábitos dos indivíduos e, até que ponto a incorporação das NTIC na sociedade (re)significou as relações sociais. A partir de uma análise superficial é possível perceber como a quantidade de estímulos e afazeres apresentados na rotina desses jovens, os coloca em um ritmo de atividades que os mantém ocupados o tempo todo. Desse modo, o lazer e diversão muitas vezes são desempenhados durante o trajeto de casa para a escola e vice e versa (jogando videogame ou ouvindo música pelo celular).

Estar conectado o tempo todo se tornou uma necessidade básica para eles? Muitas atividades como alimentação e higiene são desempenhadas enquanto eles utilizam o Facebook, Whatsapp e games por meio dos dispositivos de celular, como relatado nos diários. A maioria dos estudantes possuem TV e Internet em casa, o que facilita esse tipo de relação. Portanto, na experiência dos estudantes com as NTIC apontam uma variedade de utilização e significação para essas tecnologias: como forma de entretenimento, interagir virtualmente com amigos, estudar e fazer trabalhos escolares.

O conteúdo programático mobilizado pelas aulas proporcionou novas reflexões: Qual a relação e as fronteiras criadas entre o "real" e "virtual" para os jovens estudantes? Quais são os novos padrões de interações sociais estabelecidas após a incorporação destas tecnologias no cotidiano dos indivíduos? Quais os impactos dos estímulos mediados pelos dispositivos técnico-científicos comunicacionais no indivíduo e nas relações sociais? Tais impactos podem suscitar mudanças na percepção cognitiva e no processo de aprendizagem e de percepção de mundo? Estas questões nortearam a discussão final da sequência didática mobilizando o tema "tecnologias e mídia".

O professor discutiu, com base no livro didático, sobre os avanços tecnológicos proporcionados pela "revolução técnico-científica informacional" - vista como terceira revolução industrial. Segundo alguns autores, tal revolução teve início no final do século XIX e ao longo de todo o século XX, quando novas descobertas provocaram mudanças radicais na comunicação entre as pessoas (ZENUN \& MARKUNAS, 2013, p.13).

Nesse contexto, surge um tipo de comunicação em rede, tornando favorável o surgimento de vínculos e interações sociais à distância e, ainda, possibilitando a criação de laços sociais por meio de comunidades virtuais. O uso das ferramentas disponíveis na internet abriu a possibilidade de os indivíduos se "conhecerem" e estabelecerem 
relacionamentos sem qualquer contato físico anterior. As Novas Tecnologias de Informação e Comunicação modificaram os hábitos das pessoas e alteraram a percepção delas em relação ao tempo, ao espaço e aos outros, produzindo novas formas de sociabilidade (CASTELLS, 1999; LÉVY, 2003).

Contudo, a discussão em torno da relação entre NTIC e as interações sociais nas sociedades contemporâneas consolidaram a culminância da sequência didática de cinco aulas, desenvolvidas a partir da disciplina sociologia, tendo como recurso didáticopedagógico o diário de campo enquanto técnica de pesquisa mobilizada pelo método etnográfico, difundido pela Antropologia.

\section{O diário de campo para a antropologia}

O uso do diário de campo como instrumento de coleta de evidências é fundamentado pelo método etnográfico e muito utilizado em pesquisas antropológicas. A intenção didático-pedagógica em utilizar o diário de campo foi para estimular a participação dos estudantes e, ao mesmo tempo, aproximar conceitos e teorias mobilizadas pela disciplina sociologia. Ainda, objetivou-se estimular a observação do familiar através de técnicas e métodos científicos mobilizados pelas ciências sociais.

O diário de campo, enquanto técnica de coleta de dados foi difundida através da pesquisa social realizada pelo antropólogo Bronislaw Malinowski (1910). Este polonês viajou para as Ilhas Trobriand (atóis localizados na costa oriental de Nova Guiné), onde realizou sua pesquisa de campo por cerca de cinco anos de longa convivência e aprendizagem da língua nativa e dos hábitos dos povos de lá. Sua sistemática de pesquisa social contribuiu com severas críticas dirigidas a corrente teórica-metodológica pautada no "evolucionismo social".

Malinowski por meio da "observação participante" e do "diário de campo" realizou uma análise do complexo sistema de trocas econômicas e simbólicas presentes na cultura dos "argonautas" trobriandeses (MALINOWSKI, 1976, p. 35). Por meio do convívio, reflexão e anotação no diário das impressões e evidências observadas durante seu trabalho de campo, este antropólogo buscou compreender a dinâmica existente na lógica social dos 
trobiandeses. Assim, ele inaugurou a pesquisa etnográfica e difunde seu método e técnicas por meio de uma nova perspectiva teórica para realização de pesquisas sociais.

A partir disso, foi possível sistematizar as ações do cientista social que pretendesse conhecer e compreender uma determinada realidade social: uma vez que se tem que lidar com sentimentos, emoções e sensações sem perder de vista a objetividade metodológica. Esse caldeirão intersubjetivo pode e deve refletir nas análises do cientista social, sem deixar de estar atento as suas manifestações particulares e aos aspectos coletivos de representação de fato pertencentes à concepção do grupo pesquisado. Deve-se, portanto, enfatizar sempre “o ponto de vista do nativo" (DURHAM, 1986, p. 17-37).

Por fim, o método etnográfico seria capaz de captar a realidade cotidiana explicitada na existência dos indivíduos, através das técnicas como a "observação participante" e o "diário de campo".

\section{A experiência etnográfica dos estudantes}

Observar o conhecimento no momento em que ele é construído requer considerar os esquemas pedagógicos operados durante a interação social em sala de aula. (GOFFMAN, 1980, 1998; GARCEZ, 2011). Nesse sentido, refletir acerca da experiência social proporcionado pela sequência didática das aulas torna-se relevante para a compreensão do processo de ensino e aprendizado dos conteúdos das ciências sociais no ensino médio.

O cenário que se encontra a disciplina sociologia em escolas públicas e privadas é de despreparo dos professores e da falta de uma linguagem adaptada aos jovens do ensino médio (LEAL \& YUNG, 2015, p 779). Frente a essa realidade o presente trabalho buscou alternativas para ampliar a compreensão sobre o ensino de ciências sociais no contexto escolar. Desse modo, além de refletir acerca de recursos didático-pedagógicos, mobilização de temas, conceito e teorias em uma linguagem adaptada ao contexto da experiência social de cada aluno.

As interações face a face durante as aulas foram capazes de estimular novas formas de experimentar a própria realidade através do conhecimento mediado pelo professor, criando uma ponte entre conhecimento teórico (científico das ciências sociais) e a 
observação das vivências na cidade, os usos das tecnologias e equipamentos disponíveis no contexto social urbano (MAGNANI, 2000; 2002).

Durante as aulas os jovens foram estimulados (re)significar sua própria realidade cotidiana. Durante o processo de construção de conhecimento foram produzidas análises dos relatos dos alunos, que se tornaram protagonista e investigadores de sua própria realidade. Assim, através do exercício de produzir um texto narrando sua própria rotina o alunato foram estimulados a compreender o uso do diário de campo como uma técnica para pesquisas sociais e, ao mesmo tempo, proporcionou-lhes uma experiência etnográfica de seu familiar.

É possível dizer que a sequência das aulas proporcionou uma "experiência etnográfica" nos alunos, evocando uma "presença participativa, um contato sensível com o mundo a ser compreendido, uma relação de afinidade emocional com seu povo, uma concretude de percepção" (CLIFFORD, James, 1998, p.36). A experiência dos estudantes com as aulas, de alguma maneira, estimulou outro olhar para a relação dos indivíduos com as Novas Tecnologias de Informação e Comunicação.

Em síntese, a partir do momento em que os conteúdos das aulas foram mobilizados levando em consideração a experiência social dos estudantes e a utilização de um recurso pedagógico capaz de relacionar conceitos e teorias com a realidade destes, possibilitou um olhar estranhado de fenômenos sociais naturalizados.

\section{Considerações finais}

Vimos que o ensino de ciências sociais, instituído por lei no currículo escolar para os três últimos anos da educação básica, trouxe novos desafios aos professores cientistas sociais. Entre os desafios podemos destacar a transposição linguística dos conhecimentos produzidos pelas ciências sociais e o uso metodologias de ensino e recursos compatíveis à realidade desse novo público.

Diante disso, o presente trabalhou e buscou traçar algumas reflexões e análises envolvendo uma sequência didática de cinco aulas na turma do primeiro ano de uma escola privada, localizada na cidade de Ponte Nova, MG. Além do tema trabalhado nas aulas 
buscou-se refletir sobre o uso do diário de campo como um recurso didático-pedagógico para a disciplina sociologia.

Foi possível observar nas experiências face a face na sala de aula que o professor mobilizou o tema "tecnologias e mídia" relacionando-o aos conceitos e teorias presentes no livro didático da disciplina. Assim, para garantir a compreensão dos fenômenos sociais envolvendo os habitus dos indivíduos e as novas tecnologias de informação e comunicação, o docente buscou através da produção dos diários de campo contextualizar as aulas com a realidade dos jovens.

A experiência de descrever no diário um dia da rotina semanal dos estudantes estimulou uma observação do familiar pela lente das ciências sociais. Tal movimento, até certo ponto, levou o alunato a estranhar algumas de suas práticas cotidianas. A partir da leitura dos diários em sala de aula o professor provocou nos estudantes questionamentos através de conceitos próprios da sociologia. Além disso, cada um passou a conhecer mais de perto a rotina dos colegas e, com a mediação do professor, a refletir sociologicamente sobre os hábitos sociais envolvendo as NTIC.

\section{Referências}

BERGER, Peter. Perspectivas sociológicas: uma visão humanística. Petrópolis: Vozes, 1978.

BOURDIEU, Pierre. Escritos de Educação. Petrópolis: Vozes, 2008.

. Os usos sociais da ciência: por uma sociologia clínica do campo científico. São Paulo: Editora UNESP, 2004.

BRASIL, Lei No 9.394 de 20 de dezembro de 1996, que estabelece as diretrizes e bases da educação nacional. Diário Oficial da União. Seção 1 - 23/12/1996, p. 27833, Brasília-DF, 1996.

. Lei 11.684 de 2 de junho de 2008, que altera o art. 36 da Lei ${ }^{\circ} 9.394$, de 20 de

dezembro de 1996, que estabelece as diretrizes e bases da educação nacional, para incluir a Filosofia e a Sociologia como disciplinas obrigatórias nos currículos do ensino médio. Diário Oficial da União - Seção 1 - 3/6/2008, p. 1 (Publicação Original), Brasília-DF, 2008.

CASTELLS. Manuel. A sociedade em rede. Trad. Roneide Venâncio Majer. São Paulo: Paz e Terra, 1999. 
CLIFFORD. James. A experiência etnográfica: antropologia e literatura no século XX. 4. ed. Rio de Janeiro: editora UFRJ, 2011.

DAMATTA. Roberto. Relativizando: Uma introdução à antropologia social. Rio de Janeiro: Rocco, 1987.

DOLZ. J; NOVERRAZ. M; SCHENEUWLY. B. Sequência didática para o oral e a escrita: apresentação de um procedimento. In: ROJO. R; CORDEIRO. G. S (Orgs.). Gêneros Orais e Escritos na Escola. Campinas: Mercado das Letras, 2004.

DURHAM, Eunice Ribeiro. A reconstituição da realidade. São Paulo: Ática, 1978.

. A pesquisa antropológica com populações urbanas: problemas e perspectivas. In: CARDOSO, Ruth (org.). Aventura Antropológica: teoria e pesquisa. Rio de Janeiro: Paz e Terra, 1986. p. 17-37.

GARCEZ, Pedro M. Pedir e oferece ajuda para 'fazer aprender' em atividades pedagógicas de encenação na fala-em-interação de sala de aula de inglês como língua adicional. In: BARCELOS, Ana M. F. (org.). Linguística Aplicada: Reflexões sobre ensino e aprendizagem de língua estrangeira. Campinas: NPLA, 2011.

GOFFMAN, E. A representação do eu na vida cotidiana. 16. ed. Petrópolis: Vozes, 2009.

. A Elaboração da Face. In: FIGUEIRA, Sérvulo A (org.). Psicanálise e ciências sociais. Rio de Janeiro: Livraria Francisco Alves Editora S.A, 1980.

Footing. In: GARCEZ, Pedro M. \& RIBEIRO, Branca T. (org.). Sociolinguística interacional: antropologia, linguística e sociologia em análise do discurso. Porto Alegre: AGE, 1998.

LÉVY, P. A inteligência coletiva: por uma antropologia do ciberespaço. 4. ed. São Paulo: Loyola, 2003.

Cibercultura. 2. ed. São Paulo: Editora 34, 2000.

MAGNANI, José Guilherme C. Quando o campo é a cidade: fazendo antropologia na metrópole. In: MAGNANI, J. G \& TORRES, Lilian. Na metrópole: textos de antropologia urbana. São Paulo: Edusp/Fapesp, 2000. p. 13-53.

De perto e de dentro: notas para uma etnografia urbana. Revista Brasileira de Ciências Sociais, v. 17, n. 49, p. 11-29, 2002.

MALINOWSKI, B.. Argonautas do Pacifico Ocidental. São Paulo: Abril, 1976 [1922].

MORAN, José Manuel, MASETTO, Marcos e BEHRENS, Marilda. Novas Tecnologias e Mediação Pedagógica. 12. ed. Campinas: Papirus, 2006, p.11-65. 
SARANDY, Flávio M. S. Reflexões acerca do sentido da sociologia no Ensino Médio. Desenvolver a perspectiva sociológica: objetivo fundamental da disciplina no Ensino Médio. Revista Espaço Acadêmico, ano I, n. 5, outubro. 2001. Disponível em: <http://www.espacoacademico.com.br/005/05sofia.htm> . Data de acesso: 18/07/2016.

VELHO, Gilberto. Observando o familiar. In: NUNES, Edson (org.). A aventura sociológica. Rio de Janeiro: Zahar, 1978.

ZENUN, K. HAMADA \& MARKUNAS, M. Caderno de Sociologia 3 - Indústria Cultural. Brasília: CisBrasil - CIB, 2013. 